IJLRES - International Journal on Language, Research and Education Studies ISSN: 2580-6777 (p); 2580-6785 (e)

Vol. 1, No. 2, 2017

Page: $322-337$

\title{
THE JOURNEY OF TEACHING NON-ENGLISH SPEAKING LEARNERS FROM A FOREIGN COUNTRY
}

\author{
Lynnette A. Ejem \\ Bukidnon State University, Malaybalay City, Philippines \\ lynnetteasuncion26@gmail.com \\ Iris April L. Ramirez \\ Bukidnon State University, Malaybalay City, Philippines \\ irisaprilramirez@gmail.com \\ Cesar B. Ortiz \\ Bukidnon State University, Malaybalay City, Philippines \\ cesarbaylinortiz@gmail.com
}

\begin{abstract}
The study explored the experiences of the Trainers during their conduct of Summer Training with Thai Elementary teachers on May 2016 and April 2017 at Bukidnon State University (BukSU), Malaybalay City, Philippines. The Summer Training was conducted to teach the Thai teachers English Communication Arts; Mathematics and Science using English language. The challenges, difficulties and problems encountered by the BukSU Trainers in training Thai Teacher-Trainees as English second language (ESL) learners, were determined as well as the interventions utilized by the Trainers to address their encountered challenges/difficulties/problems. Narrative qualitative analysis was employed to gather data. From the narratives of the Trainers, trends and patterns were established to analyze and interpret the results. Data revealed that the encountered challenges by BukSU Trainers in training the Thai Trainees include language barrier, the Trainees' difficulty in understanding English language and how to effectively teach content in math and science using English language. The difficulties/problems encountered by the Trainers were addressed through teaching strategies and approaches that promoted active participation; involved minds-on, hands-on, and experiential learning activities; and exposed the Thai Teacher-Trainees to reallife situations.
\end{abstract}

Keywords: English as second language (ESL) learners, challenges, interventions, Thai Teacher-Trainers, Thai Trainees

\section{INTRODUCTION}

Studies in second language acquisition have shown that a second language is best learned through content when learners have a purpose for learning and when language use is authentic, rich and meaningful 1. Non-native English-speaking

\footnotetext{
${ }^{1}$ Ren Dong, Y 2002. Integrating language and content: How three Biology teachers work with non-English speaking students. International Journal of Bilingual Education and Bilingualism, 5:40-57.
} 
learners benefit more from learning the second language and academic content knowledge simultaneously rather than separately. This brings in an alternative to code switching especially in a multicultural setting, namely Content and Language Integrated Learning (CLIL), which has established itself in the European discourse about educational practice ${ }^{2}$.

Content and Language Integrated Learning involves teaching a particular subject such as Sciences or Mathematics wherein the medium of a language is not the first language of learners. This was true to the Thai teachers who came to BukSU for the summer training on teaching English Communication Arts, Mathematics and Science using English Language. The Trainers were the Faculty members of BukSU who have the expertise in content of the said subjects. The Thai teachers being the participants of the one-month training were ESL-Trainees or non-native speakers of English, being used as the medium of instruction during the training.

Mathematics and science classrooms based on inquiry and problem solving hold special promise and challenge for ESL (English as second language)-learners. Scientific inquiry and mathematical problem solving are suffused with talk: questioning, describing, explaining, hypothesizing, debating, clarifying, elaborating, and verifying and sharing results. While the language demands are significant, the potential is also strong that students will learn important English-language skills as well as science and math content ${ }^{3}$. Science, on the other hand, is recognized as a highly communicative discipline, where language is central to the collaborative nature of scientific discourse. However, there is an established way of "talking science." Language conventions are evident in the way learners argue or debate in science; the way they offer hypotheses or communicate inferences; the way they negotiate meaning by questioning, paraphrasing, or elaborating during scientific discourse 4 .

\footnotetext{
${ }^{2}$ Dalton-Puffer, C. (2007). Outcomes and processes in content and language integrated learning (CLIL): current research from Europe. In: Delanoy W \& Volkmann L (eds). Future perspectives forEnglish language teaching. Heidelberg: Carl Winter.

3 Buxton, C.A. (1998). Improving the science education of English language learners: Capitalizing on educational reform. Journal of Women and Minorities in Science and Engineering, 4(4), 341-369.

${ }^{4}$ Laplante, B. (1997). Teaching science to language minority students in elementary classrooms. New York State Association for Bilingual Education Journal, 12, 62-83. Retrieved Sept. 2, 2015 from www.ncbe.gwu.edu/miscpubs/nysabe/vol12/nysabe124.pdf.
} 
Attaining scientific literacy must be viewed as central to education reform ${ }^{5}$ as this is considered a way to empower citizens towards economic gain (Ayala, 2005). Thailand is highly motivated to strengthen its economic position in the world market, which requires developing a world-class quality education system. A scientificallyliterate public can enhance a country's market position ${ }^{6}$, but extensive science knowledge is written in English that need to be accessed by English in Foreign Language (EFL) countries. Thus, education reform in EFL countries are beginning to target the foundational levels of learning such as primary education with specialist teachers who can focus on science education and mathematics education using English as the Medium of Instruction (EMI) and this is one of the thrusts of ASEAN 2015.

English literacy development, science education, and mathematics education must be core elements in EFL preservice teacher education if economic enhancement is a national focus for international development ${ }^{7}$ (Hudson, 2009). Thus, the Summer Training Program for Thai Teachers was very timely to help them meet the thrusts of ASEAN 2015 and to keep up with the changing times. The Anubanchonburi School in Thailand sent to BukSU 16 Thai teachers as participants in Summer 2014; 25 Thai teachers in Summer 2015; 14 Thai teachers in Summer 2016 (2 came from Anubanpetchaburi School); and 17 Thai teachers in Summer 2017.

The summer training of the Thai teachers was aimed to immerse them to situations that would enable them to speak and converse in English; to train Thai teachers on the Mathematics concepts in English and on the application of teaching strategies in Mathematics; and to capacitate the Thai teachers on the science concepts in English and on the strategies in teaching Science. The summer training for the Thai teachers had posed some challenges to BukSU Trainers on training the Thai teachers, who come from a foreign country, being second language learners.

In this study, the BukSU Trainers shared their experiences- challenges and difficulties/problems in their journey of training the Thai elementary teachers. This study may provide significant information to other Trainers and Teachers who are

\footnotetext{
${ }^{5}$ Pattanayak, V. (2003).Physics first in science education reform. Journal of Young Investigators, 7.

${ }^{6}$ Bischoff, P. J.; Hatch, D. D.; \& Watford, L. J. (1999). The state of readiness of initial level

${ }^{7}$ Hudson, P. (2009). Learning to Teach Science Using English As Medium of Instruction. Eurasia Journal of Mathematics, Science and Technology Education, 5 (2), 165-170.
} 
teaching English, mathematics, and science in English to preservice teachers and to other English second language learners (ESL).

\section{Objectives}

This study explored the experiences encountered by the Thai Teacher-Trainers during their summer training to teach Communication Arts, Mathematics and Science in English language. This was conducted on May 2016 and April 2017 at Bukidnon State University with Thai elementary teachers.

Specifically, this answered the following questions:

1. What are the challenges and difficulties/problems encountered by the Teacher Trainers (in English, mathematics and science) in training the Thai TeacherTrainees as ESL-learners?

2. What are the interventions used by the Trainers to address their encountered difficulties/ challenges?

\section{METHODOLOGY}

This study employed qualitative research design using narrative analysis. Narrative research is a term that subsumes a group of approaches that in turn rely on written or spoken words or visual representation of individuals. Narratives or stories occur when one or more speakers engage in sharing and recounting an experience or event. Narrative analysis takes the story as the investigative focus. Narratives or stories may be oral or written; be elicited, for example during an interview, or naturally occurring; be very short or long; be told as a way to share one's bibliography; focus on events and the meaning of those events; focus on the ordinary stories people tell as a way to share experiences ${ }^{8}$ (Chase, 2005). A qualitative approach makes it possible to study "things in their natural settings, attempting to make sense of or interpret phenomena in terms of the meanings people bring to them" (Denzin \& Lincoln, 2005).

Directed interviews on the experiences and challenges/difficulties/problems encountered by the Trainers in teaching English communication arts, mathematics, and science using English language, respectively, were conducted. The interventions

\footnotetext{
${ }^{8}$ Chase, S. E. (2005). "Narrative Inquiry: Multiple lenses, approaches and voices." In N.K. Denzin \& Y.S. Lincoln (Eds). The Sage Handbook of Qualitative Research ( $3^{\text {rd }}$ Edition), pp. 651- 679. Thousand Oaks, CA: Sage Publications.
} 
and strategies being implemented by the English, science and math Trainers to address the challenges and difficulties/problems of the Thai-Trainers were also identified and documented. Themes and categories of the challenges/difficulties/problems and interventions provided by the Trainers were established and justified based on the data gathered. Pattern on the interventions utilized by the Trainers in addressing the challenges/difficulties/problems in teaching the Thai Trainees using English language were based on the responses of the BukSU Trainers in English, mathematics, and science.

Focus group interviews were also conducted. Focus groups were structured small group interviews. According to Taylor-Powell (2002) they were "focused" in two ways. First, the persons being interviewed are similar in some way, just like the Thai trainers who were experts in their respective fields (English, Math and Science) and were proficient English speakers; second, the purpose of the interview was to gather information about a particular topic guided by a set of questions. The participants hear and interact with each other. They give either different or similar information and could expound on their responses, than if they were individually interviewed.

The purpose of focus group interviews was to develop a broad and deep understanding rather than a quantitative summary. The emphasis was on insights, responses and opinions. In this study, there were six participants for the focus interview, 2 Trainees from each subject. The participants (BukSU Trainers) were considered experts in their fields, having taught the subject for not less than 5 years and at least had a master's degree.

The interview was started with a probing question: What are your experiences as Trainer of the Thai teacher-trainees in English/Math/Science? The other questions asked were - What difficulties/problems did you encounter as Trainer of the Thai teacher-trainees? What intervention procedures/processes did you use to address the difficulties/problems you encountered as Trainer of the Thai trainees? The BukSU Trainers were encouraged to speak their minds and to expound further their answers. The responses from the focus group interviews were recorded and analyzed based on the patterns or trends derived from the data. At the end of the interviews, all participants were thanked for their involvement. 


\section{DISCUSSION AND FINDINGS}

The BukSU Trainers' Challenges/Difficulties/Problems in Teaching the Thai Trainees

On the Language Factor. One of the major difficulties encountered by the Trainers during the training was the language barrier. According to the Trainers, majority of the Thai trainees could hardly communicate in English. Their spoken English was not intelligible because of misarticulation. During the early part of the training, the Trainers were quite frustrated like during the speech drills in their English class because the Trainees could not articulate some sounds in English, since these are not present in their language, resulting in mispronunciation of English words.

The Trainees had different way of pronouncing the English words being taught in English, mathematics and science subjects. It was a problem for the Trainers to decipher what the Thai trainees mean when the latter pronounced a word. The challenge was to familiarize with the letter in the word which the Trainees found difficult to utter and which syllables were stressed in their intonation.

The BukSU Trainers noted that the Thai trainees had difficulty in pronouncing letter "r". Instead of having the "R" sound, they drop it, or use "L" sound instead. The latter cannot pronounce for example "decomposer", so that it can be heard, as de-compo-se, or "decompo-sel" stressing and prolonging the last syllable. In saying "problem", the Trainee for example, either says "pombem" or "pomblem". In addition, the Trainees had a different intonation in the pronunciation of the word. Thus, it was difficult at first for the Trainers to understand what the Trainee was saying. So, when they said "teacher" they would say "te-tse...." prolonging the last syllable.

The Thai Trainees also had difficulty with double consonants for ending sounds, or with consonants in the middle of the word. For example, "st" in question, which is pronounced as "queshion"; "find" is pronounced as "fine"; thousand as "tawsan", prolonging the last syllable. The Thai Trainees also had a problem pronouncing the "st" combination leaving out the "s", such as in "cost" which becomes "caught"; in "fast", it is pronounced as "fat".

The Trainees had a difficulty with "s", being followed with a consonant such

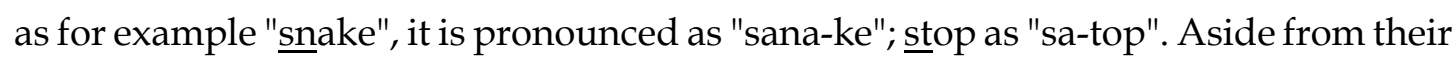
unintelligible English, they could also hardly express themselves in English in the 
actual communication situations. Later, being familiar with the Trainees' pronunciation and intonation, the Thai Trainers had understood what the Trainees were saying and the Trainers also knew how to correct the Trainees.

On the Thai Trainees' Comprehension with English language. The BukSU Trainers had difficulty having the Thai Trainees understand the lesson, since they could not grasp what the Trainers were discussing using English language. It was a challenge to the Trainers to come up with activities that would enable the Trainees to be engaged in the lesson and to actively participate in the activities. For the first two weeks during the training, it took the Thai Trainees a long time to finish their tasks. They struggled in understanding the English language. However, it was later observed that they became at ease towards the remaining days of the training. The Trainers had to keep on repeating the words and to speak slowly so that the Thai trainees could catch up with the spoken English words. Majority of the Thai Trainees had difficulty understanding the instructions given by the Trainers. The Trainees also had difficulty to express their ideas in English. It was a challenge for the BukSU Trainers to enable the Thai Trainees understand the lessons and to make them convey their ideas in English language.

\section{Interventions Utilized by the BukSU Trainers}

The following interventions were being utilized by the BukSU Trainers to address the challenges/difficulties/problems they had encountered in training the Thai Teacher-Trainees, as second language learners of English language.

\section{On Language Barrier}

The BukSU Trainers utilized the following interventions to be understood and to enable the Thai Trainees teach the content using English, as medium of instruction.

Speaking slowly, distinctly, and writing down key terms. All the BukSU Trainers noticed that, "the Trainees could not understand right away the instructions being given to them". Most of the Thai Trainees claimed that "the Trainers talk too fast". Accordingly, anyone who had learned a foreign language in class, and had then traveled to a country, where the language was spoken, would have difficulty in understanding the native speakers of the language because they seemed to talk too fast. What seemed normal speed to native speakers was extremely fast to a second language learner. With this feedback, the Trainers had adjusted their speed in speaking. The words or terms being used were spoken slowly and pronounced distinctly. The Trainers also found 
the necessity to write down the key terms used, so that the learners could see them and connect them with the spoken word. It was also important to write down the key terms for the Trainees to read, and to enable them to know how to read and spell the words.

To tap a Participant/Trainee who is good in English. It was observed that among the Thai Participants/Trainees, there was at least one who was good in English language, i.e., with somebody who could easily understand English, the said Training Participant was tapped in translating, for example, the instruction given by the Trainer. The Training Participant who was good in English was requested to translate the instructions and other statements in English to Thai language, which the other Training participants could not understand. This easily facilitated the comprehension of English words as well as in the teaching of mathematics and science concepts. With the instructions and terms being understood by the Training Participants, they were able to work with their activities for the training. They had made the necessary translation of the words from Thai to English with their concerned subjects.

Having informal interaction in English with the Training Participants. Most of the BukSU Trainers claimed that they encouraged the Training Participants to speak in English when they respond to some of the questions asked to start a conversation when the Trainees were doing their group activity or when they were working for an output. The Trainers tried to have conversations with the Trainees on some matters that were not even directly concerned with the subject, just for the latter to answer in English. During these informal conversations, the Training Participants were encouraged to share some of their experiences, as elementary teachers in Thailand or on any event that they had back home. One Trainer said that she asked some Trainees regarding their pets at home; another Trainer shared to have conversations regarding some menu of the favorite food of the Trainees; others make conversation about the kids of the Trainees; and the like. The Trainers noticed that after some time, towards the third week of the training, the Trainees felt comfortable in speaking English, even slowly when asked to share their ideas.

Knowing about their culture. The Trainers all agreed that they had to learn about the culture of the Thai Trainees for communicating something familiar to them. The Trainers for example, had learned that the Thai Trainees had difficulty in pronouncing some English words because they were tonal in speaking Thai words. The Thai 
Trainees had to stress certain syllables as they pronounced the words in their native language. Knowledge about the traditions of Thai would also enable the Trainers to incorporate this in the lessons.

In one of the sessions in their English class, the Thai Trainees were made to share their experiences, using English language, of the famous Songkran Festival in Thailand, the celebration for New Year. They were also made to organize an activity to celebrate the festival together with the Trainers and other officials of the University. The Trainers together with the Thai Trainees wore floral clothing, which the Thai practiced during the Songkran festival in their country. The celebration became part of the Trainees' activity in their English class. In the Science class, particularly on the topic about organisms, populations and ecosystems, the Trainees had presented examples from their own country. They had shown the conditions of their environment way back home. In the Mathematics class, the activities on their topics about fraction and problem solving were being applied to their real-life situations. The Trainees gave examples of some resources being used in their country.

\section{On the Teaching of Content in English Communication Arts, Math, and Science Using}

\section{English Language}

The BukSU Trainers utilized various teaching strategies which promoted active participation. The strategies they used also involved minds-on, hands-on, and experiential learning activities; and such teaching approaches exposed the Thai Teacher-Trainees to real-life situations. The teaching and learning did not focus primarily on language learning, but also on the use of the second language to teach the subject content. Accordingly, the teachers working with second language learners should not only be specialists in their subject, rather than traditional language teachers, they also had to be fluent speakers of the target language (Hudson, 2009). In this study, the Trainers were considered experts in their respective fields and were also fluent speakers of English language. The key issue was that the learner gains new knowledge about the subject while encountering, using and learning the second language. The methodologies and approaches used were often linked to the subject area with the content leading the activities.

Strategies in Teaching English. As an intervention for the Trainees' difficulty to speak English, the English Trainers had shifted the training approach from formbased approach (teaching English grammar and sounds in discrete manner) to 
function-based approach (contextualizing the teaching of sounds, language functions and expressions through real life communication situations). One English Trainer "gave the Trainees model dialogues and communication prompts to facilitate their interaction in English." The English Trainers utilized the Communicative Language Teaching Approach that emphasized language functions in English. The lessons included performing the following communicative functions: Greeting and introducing oneself/Greetings and leave-takings; Talking about culture; Telling time; Asking for/Giving directions; Asking for information; Paying/Making orders/Asking about menus and dishes; Inquiring about flight schedule/Checking details/Buying a ticket; Haggling prices; Asking for weekend plans; Inquiring/Requesting; Asking for advice/assistance; Inviting/Accepting/Refusing; Making an appointment with a doctor; Asking for information/Inquiring about products, medicines, prices; Narrating events/Talking about past events; Describing experiences; Talking about future plans and Expressing gratitude.

In the presentation of the cited lessons, the English Trainers had organized the activities of the Training Participants into three stages: stage 1 involved with the presentation of language functions, language expressions and the language forms needed to perform them. The second stage, pre-communication stage, involved with articulation and pronunciation drills followed by mini-dialogues; and the third stage, the communication stage, had included activities like role plays, simulation, jazz chants, interview, brainstorming, games, learning journal and the like; extension activities included guided tour (going to the supermarket, wet market, hospital, pharmacy, hotel, etc.). These activities were to enable the Trainees practice their communication skills in English. The post evaluation and interview were conducted to determine areas which needed further improvement.

Some researchers had theorized that learning an additional language is very much like learning a first language. They contend that the brain may be "hard wired" or programmed to learn a language, so that, regardless of whether it's the first or subsequent language being learned, the process of acquiring it is similar (Jarrett, 1999). Therefore, much like a toddler will learn the first language in the context of daily encounters with the real world and interactions with other people, so will students learn a second language best when being learned in an authentic and interactive environment (Radford, Netten, \& Duquette, 1997). It was observed that learning 
English was fun and meaningful to the Trainees when applied to real life situations, such as letting them have a dialogue to ask for the direction to "Gaisano Mall", to ask for the price of some goods, to order for spaghetti in a fastfood, to haggle for the price of a dress or a t-shirt in the supermarket, and the like. With this strategy, the Participant Trainees were able to easily learn conversational English.

Strategies in Teaching Math. For better understanding of the Mathematical Concepts and their applications, the Trainers used varied strategies in teaching mathematics. One Trainer in Math "utilized the CPA Approach in Teaching that followed the three stages: Concrete, Picture and Abstract." The trainer further added to have also "used the PWA - Practical Work Approach; Personalized Presentation Software; Concept Mapping; STAR and other strategies". Another trainer said to have "used a lot of manipulatives like the MAP, Fraction Bars, Geo Strips." The Math Trainers also made use of literary pieces in teaching the concepts, like songs, jazz chants, riddles, rhymes and poems. The Training Participants were made to compose their own songs, poems and rhymes about Math concepts. Some of these strategies were used for instruction as well as alternative forms of assessment. Assessments were conducted before, during and after every session, either as a class, in groups and individually.

Strategies in Teaching Science. The Science Trainers utilized the 5 E's instructional model in the training of the Thai teachers. They utilized the 5 stages in this model, namely: Engage, Explore, Explain, Elaborate and Evaluate. Various science concepts were being taught using the 5 E's model. The Science Trainers had developed science lessons incorporating the 5 Es. Bybee et al. (2006) averred that using the 5 E's instructional model would aid the learners build or construct new ideas on top of their old ideas. The 5 Es could be used with learners of all ages, including adults. Each of the 5Es describes a phase of learning. The 5 E's instructional model allows the learners and the teachers to experience common activities, to use and build on prior knowledge and experiences, to construct meaning, and to continually assess their understanding of the concepts.

Hanuscin \& Lee (2007) alleged that using the 5Es instructional model would play a vital role in helping the students' sequential learning to bridge prior knowledge and new concepts. They added further that in designing $5 \mathrm{E}^{\prime} \mathrm{s}$ lesson, one has to incorporate the following stages: (1) engagement, where the teacher engage students in a new concept using short activities or questions that promote curiosity and draw out 
prior knowledge in order to unveil student's pre-existing knowledge; (2) exploration, where students not only conduct activities such as minds-on activities, group discussion, hands-on activities, role playing and analogies by means of their own preexisting knowledge, but also explore questions and implement a preliminary investigation; (3) explanation, where the teacher has an opportunity to directly introduce a concept, process or skill so that students utilize their understanding of the concept or track their correct and incorrect knowledge; (4) elaboration, where students try to advance their newly structured knowledge into a deeper and broader understanding in order to elaborate on their conceptual understanding and skills; (5) evaluation, where students' comprehension and abilities are assessed and thereby the teacher is able to monitor how the students have progressed in accomplishing the educational objectives.

In the training of Thai Trainees, the Trainers or Science facilitators employed the following: for Engage stage, video clips with accompanying worksheets, Q \& A and games were utilized; in Explore stage, the trainees were made to answer the questions in worksheets based on the video clip presentation, answer crossword puzzles, they were also made to data mining/internet exploration, flipbook making and games; in Explain stage, Trainees were made to think-pair and share, they were made to present their answers in the worksheets to the whole group and have to discuss their answers in English language, they were also made to present and explain their other individual and group outputs to the whole class; in Elaborate stage, students were made to do out-door and community-based activities, role playing, hands-on activities; and in Evaluate stage, different alternative forms of assessment were implemented such as spelling test with science vocabulary, the use of concept maps, poems, jingle, model-making, poster making, role playing, and oral presentation.

With the 5 E's lessons designed by the Science Trainers, it was observed by the Trainers that, "the Thai trainees were actively engaged in the learning of science concepts; the varied activities enabled the Trainees to actively participate in the lessons; they were learning not only from the Trainer but also from their groupmates; they have used their previous knowledge and experiences in the construction of new knowledge and they utilized technology (use of gadgets and internet) to help them understand science concepts and to convey their ideas in English". 
Use of technology and multimedia. All Trainers found it very useful to use technology and multimedia in the presentation of their lesson. A lot of visuals with the use of pictures, graphs, drawings, charts, figures, power point presentation, video clips with animation and translation, graphic organizers (Venn diagram, concept map, mind map, flow charts, etc.) could easily help convey the meaning of the English terms as well as the science and math concepts. These visuals and multimedia had facilitated the understanding of more technical terms in the content subjects. For example, in the science class, the concepts about earthquakes, faults and the flow of energy in the ecosystem through the food chain were easily understood by the Training Participant due to the video clips being presented by the Trainer/Facilitator. In some activities, the Trainees were also able to present their ideas through drawings. They were made, for example, to draw and explain the condition in their homes before and after an earthquake. They were made to draw and present their poster on how they could manage their garbage or household waste.

The training room was provided with Internet connection. The Trainees had their cell phones and iPods to easily translate some science terms to Thai language. Using the translator of their gadgets, the Trainees used code switching and the translation method. From Thai language, with the help of the translator, the Trainees could translate some of their answers to English language. The use of technology was found very helpful for the Trainers to enable the Thai trainees convey their ideas/answers in their science and math activities from their Thai language back to the English language.

Encouraging interaction and active participation. As presented in the cited teaching strategies being utilized by the trainers, the teaching strategies allowed the Thai Trainees to interact with each other and to be actively engaged in the activities. In their English class, for example, the Trainees had to discuss with each other how to go about with their dialogues, like in making an appointment with a doctor; asking for information/inquiring about products, medicines, prices; narrating events/talking about past events; describing experiences; talking about future plans and expressing gratitude, etc. With the language function activities in English, the Trainees had to interact with other Trainees. They need to ask guidance from their facilitator and to interact with the other people with whom they need to practice their dialogue in the natural setting. 
In their science class for instance, the Thai Trainees were made to discuss among themselves how to come up with their output in making and presenting their food chain mobile, what words to use in making their jingle or poem about ecosystems. They discussed with each other in their small groups how to role play on what to do when there is a disaster, such as fire, earthquake, flood, etc. In their Math class, an example was, when they had to plan and discuss how to present in a song the concepts they had learned about fractions or about their lesson on whole numbers, etc. In answering the worksheets in their classes, all of the Trainers said that, "the Thai Trainees had to ask their facilitators on items that need clarification and they also had to discuss with groupmates to come up with the answer, which need to be written and orally presented in English."

There were activities in the classes where the Thai Trainees were made to "think-pair-and share". The Trainers asked some questions about the lesson in math and science; and, the Thai Trainees had to discuss it with a partner. They would then share their answer to the whole class. The sharing had to be done orally using English language. Many activities being employed by the Trainers in the 3 subject areas had enabled the Trainees to practice English in writing and in speaking. Setati et al. (2002) pointed out that learning from talk is significantly limited if it is not supported or complemented with strategies for learning to talk, in other words, learning subjectspecific formal discourses. The authors added that the teachers should be able to use methods and strategies to assist ESL learners in their classrooms and they therefore need more exposure and guidance in their training to do so. In the training of the Thai Teacher-Trainees, other varied activities in the 3 subject areas were given (refer to the cited strategies) by the Facilitators to enable the said Trainees to be actively engaged in the lessons and to practice the use of English language, while learning the content in science and mathematics.

\section{CONCLUSION}

Having the task of teaching with Communication Arts, the content in Math and in Science with Educators who are English second language (ESL) learners coming from a foreign country would be challenging and overwhelming for the Trainers. The challenges could stem from various factors including language barrier, difficulty of ESL learners in understanding spoken English words and how to 
effectively teach the content in Math and Science using English Language. The Trainers should be able to integrate language and content, i.e., science and math concepts and to create authentic contexts for language learning. For meaningful learning among the ESL-Trainees, the Trainers have to employ teaching strategies that would enable the Trainees to actively participate in the activities, to practice the learners' speaking and written skills in English, and to apply content in real-life situations. The Trainers need to utilize such teaching approaches that would develop the Trainees' English language skills, and at the same time learn the content in math and science.

\section{BIBILIOGRAPHY}

Ayala, F. J. (2005). Scientific Literacy. American Scientist, 92 (5).

Bischoff, P. J.; Hatch, D. D.; \& Watford, L. J. (1999). The state of readiness of initial level preservice middle grades science and mathematics teachers and its implications on teacher programs. School Science and Mathematics, Bowling Green, 99 (7), 394-3999.

Buxton, C.A. (1998). Improving the science education of English language learners: Capitalizing on educational reform. Journal of Women and Minorities in Science and Engineering, 4(4), 341-369.

Bybee, R. N. (2006). The BSCS 5E's Instructional Model: Origins, Effectiveness and

Application. Retrieved on April 12, 2014 from htt://www.pdf/bscseesummart.pdf.

Chase, S. E. (2005). "Narrative Inquiry: Multiple lenses, approaches and voices." In N.K. Denzin \& Y.S. Lincoln (Eds). The Sage Handbook of Qualitative Research (3 $3^{\text {rd }}$ Edition), pp. 651- 679. Thousand Oaks, CA: Sage Publications.

Denzin, N. K. \& Lincoln, Y. S. 2005.The Sage Handbook of Qualitative Research. Thousand Oaks: Sage.

Dalton-Puffer, C. (2007). Outcomes and processes in content and language integrated learning (CLIL): current research from Europe. In: Delanoy W \& Volkmann L (eds). Future perspectives forEnglish language teaching. Heidelberg: Carl Winter. 
Hanuscin, D. L. \& Lee, M.H. (2007). Challenges and Scaffolds for Helping Prospective Teachers Design Science Lessons Using the 5E Instructional Approach. Association for Science Teacher Education, Clearwater., FL.

Hudson, P. (2009). Learning to Teach Science Using English As Medium of Instruction. Eurasia Journal of Mathematics, Science and Technology Education, 5 (2), 165-170.

Jarret, D. 1999. Teaching Mathematics and Science to English-Language Learners. Northwest Regional Educational Laboratory: Mathematics and Education Center.

Laplante, B. (1997). Teaching science to language minority students in elementary classrooms. New York State Association for Bilingual Education Journal, 12, 6283. Retrieved Sept. 2, 2015 from www.ncbe.gwu.edu/miscpubs/nysabe/vol12/nysabe124.pdf.

Pattanayak, V. (2003).Physics first in science education reform. Journal of Young Investigators, 7 .

Radford, L., Netten, J., \&Duquette, G. (1997). Developing target second language skills through problem-solving activities in mathematics. New York State Association for Bilingual Education Journal, 12, 84-97. Retrieved August 27, 2017 from www.ncbe.gwu.edu/ miscpubs/nysabe/vol12/nysabe125.pdf.

Ren Dong, Y 2002. Integrating language and content: How three Biology teachers work with non-English speaking students. International Journal of Bilingual Education and Bilingualism, 5:40-57.

Setati, M.; Adler, J.; Reed, Y. \&Bappo, A. (2002). Incomplete journeys: code switching and other language practices in mathematics, science and English language classrooms in South Africa. Language and Education, 16: 128-149.

Taylor-Powel, E. (2002). "Program development and evaluation. Focus group interviews." Quick tips \#5. 